\title{
SUTASOMA
}

\section{Citra Perempuan dan Bias Gender dalam Novel Juminem Dodolan Tempe Karya Tulus Setiyadi}

\author{
Siti Nur Aisyah ${ }^{\star 1}$, Widodo ${ }^{2}$ \\ 1,2Program Studi Sastra Jawa, Fakultas Bahasa dan Seni, Universitas Negeri Semarang
}

\section{Info Artikel}

\section{Article History:}

Diajukan January 9, 2019

Diterima June, 302019

Terbit June, 302019

\section{Kata kunci:}

bias gender;

citra perempuan;

perempuan jawa

\begin{abstract}
Abstrak
Novel Juminem Dodolan Tempe karya Tulus Setiyadi memiliki keunikan tentang perempuan berperan ganda yang menyeimbangkan peran domestik dan publik serta bagaimana ia menghadapi bias gender. Hal ini nampak pada perjuangan Juminem dalam menyeimbangkan peran domestik publik dan sikapnya menghadapi bias gender. Tujuan penelitian ialah menemukan, menganalisis, dan mendeskripsikan citra perempuan idaman dan sikapnya dalam menghadapi persoalan dalam kontruksi sosial bias gender. Penelitian menggunakan pendekatan objektif dengan teori citra perempuan dan bias gender. Data penelitian ini adalah bagian novel yang mengandung citra dan bias gender, sedangkan sumber data penelitian adalah novel Juminem Dodolan Tempe. Pengumpulan data dilakukan secara pembacaan semiotik, heuristik. Analisis data dilakukan secara pembacaan hermeneutik. Hasil penelitian menunjukkan bahwa 1) terdapat citra fisik, citra psikis, dan citra sosial terhadap tokoh perempuan; 2) sikap tokoh menghadapi bias gender dalam novel yang meliputi marginalisasi, stereotip, subordinasi, kekerasan, dan beban kerja. Beberapa citra Juminem ialah cantik, ulet, sabar, tegas, dan ngemong. Beberapa citra Mbok Joyo Pangat ialah perempuan yang mengunggulkan materi, sombong, dan kerja keras. Beberapa citra Minah ialah modern dan suka bepergian. Juminem mampu membela diri ketika ia dituduh jualan "tempe" oleh suaminya sendiri. Minah mampu mematahkan stereotip bahwa perempuan yang suka bepergian adalah perempuan buruk. Mbok Joyo Pangat memiliki kemampuan seimbang antara bekerja dan merawat anaknya meskipun ia janda.
\end{abstract}

\begin{abstract}
Juminem Dodolan Tempe is an novel by Tulus Setiyadi has a uniqueness about women having a dual role that balances domestic and public roles and how he faces gender bias. This is evident in Juminem's struggle to balance public domestic roles and her attitude towards gender bias. The research objective is to find, analyze, and describe the image of the ideal woman and her attitude in dealing with problems in the construction of social gender bias. The study uses an objective approach with women's image theory and gender bias. The data of this study are novel parts that contain gender images and biases, while the research data sources are Juminem Dodolan Tempe novel. Data collection is done by semiotic reading, heuristics. Data analysis was carried out by hermeneutic reading. The results of the study show that 1) there are physical images, psychological images, and social images of female figures; 2) character attitudes face gender bias in novels which include marginalization, stereotyping, subordination, violence, and workload. Some of Juminem's images are beautiful, resilient, patient, firm, and snacking. Some of the images of Mbok Joyo Pangat are women who favor material, arrogant, and hard work. Some of the images of Minah are modern and like to travel. Juminem was able to defend herself when she was accused of selling "tempe" by her own husband. Minah is able to break the stereotype that women who like to travel are bad women. Mbok Joyo Pangat has a balanced ability between working and caring for her child even though she is a widow.
\end{abstract}




\section{PENDAHULUAN}

Perkembangan studi gender dapat dilihat melalui karya sastra. Salah satu novel yang membahas mengenai perempuan modern dan sikapnya dalam keluarga serta masyarakat dalam menghadapi permasalahan ialah novel Juminem Dodolan Tempe karya Tulus Setiyadi yang ditulis tahun 2016. Secara garis besar menceritakan tentang perjuangan seorang Juminem yang berjuang memenuhi kebutuhan ekonomi karena suaminya dipecat dari pekerjaannya. Hal itu dilakukan Juminem lantaran suaminya, Mariyanto, menjadi pengangguran, suka judi dan mabuk, sedangkan kebutuhan keluarga mendesak. Juminem, dengan segala kerepotannya berjualan tempe dan mengurus rumah tetap tabah dan sabar menghadapi tingkah laku suaminya. Semua itu dilakukan atas dasar cinta dan baktinya kepada Mariyanto.

Karya sastra ini mencoba menggambarkan bagaimana sikap dan tindakan yang diambil Juminem ketika menghadapi masalah keuangan keluarga dan bias gender di masyarakat. Apa yang dialami oleh Juminem bukan lagi hal baru yang terjadi kini. Keadaan mendesak yang sedemikian rupa menuntut Juminem harus menjadi seorang istri yang berperan ganda. Di satu sisi ia harus bekerja karena kebutuhan, di sisi lain ia juga harus mengurus keluarga sebagai kewajiban. Ia merasakan bahwa peran ganda yang dijalankannya berat (Setiyadi, 2016: 2).

Namun Juminem tidak pernah mengeluh. Sebagai seorang wanita ia begitu tegar menghadapi Mariyanto dan dunia kerja pasar tempat ia berjualan tempe. Orang lain menilai bahwa selama ini dia pasti tidak hanya berjualan tempe saja untuk memenuhi kebutuhan keluarganya. Setidaknya ia pasti berjualan 'tempe' lain. Pelabelan negatif itu ia dengar dari perkataan orangorang yang tanpa sengaja ia dengar di pasar malam. Tentu saja ia geram mendengar dirinya dituduh sebagai seorang pelacur melalui konotasi makna 'tempe' yang dalam bahasa Jawa berarti alat kelamin perempuan.

Sebagai perempuan yang tidak ingin gegabah, Juminem mencoba menelusuri siapa orang yang telah menyebarkan rumor tersebut. Lantas ia memberikan pelajaran yang setimpal atas tuduhan yang telah diterimanya. Di sini menunjukkan bahwa sebagai perempuan ia tidak tinggal diam dan berpasrah diri saat harga dirinya dilecehkan. Ia bahkan berani melawan Mariyanto yang menuduhnya berbuat serong lantaran uang tabungannya banyak.

Ketika perempuan menjalani perannya sebagai ibu rumah tangga sekaligus pekerja, mereka menganggap bahwa hal tersebut adalah suatu kondisi yang wajar dan harus diterima (Koesbandijah et al, 2013: 12-14). Pernyataan tersebut tepat pula bagi Juminem. Ia merasa bahwa meskipun ia bekerja, ia tidak boleh melupakan tangungjawabnya sebagai ibu rumah tangga beserta segala aspek di dalamnya. Studi kasus yang dilakukan oleh Koesbandijah di kampung miskin Dukuh Kayon, Desa Batursari, Kecamatan Mranggen, Demak menunjukkan bahwa posisi perempuan masih tersubordinasi dibawah pengaruh laki-laki. Dalam kemiskinannya, perempuan-perempuan tersebut menganggap wajar bila dirinya juga harus ikut bekerja membantu sang suami. Perempuan-perempuan dalam kondisi tersebut tentu memiliki beban yang lebih berat.

Lantara (Lantara, 2015: 4) mengemukakan bahwa perempuan masa kini tak hanya duduk manis dalam rumah, sebagian besar telah memiliki peran ganda sebagai wanita karir sekaligus penanggungjawab rumah tangga. Hal serupa terkait peran perempuan Jawa di ranah domestik dan publik juga dikemukakan oleh Permanadeli (2015: 216). Peran ganda yang dipilih tersebut tentu ada faktor lain yang mempengaruhinya. Faktor pertama ialah faktor kebutuhan keluarga yang mendesak, sedangkan penghasilan suami masih belum mencukupi. Faktor kedua adanya keharusan istri bekerja lantaran suaminya cacat atau tidak mampu bekerja, cerai, meninggal, maupun pengangguran. Ketiga ialah faktor dimana perempuan merasa perlu mengaplikasikan ilmu pengetahuan yang dimilikinya di masyarakat tanpa membuat keluarganya terbengkalai. Dalam kasus novel Juminem, ia bekerja karena faktor pertama.

Sebuah studi yang dilakukan oleh Permanadeli (2015) menunjukkan bahwa perempuan Jawa modern ialah mereka yang tidak meninggalkan tugas utamanya sebagai ibu rumah tangga meskipun aktif di masyarakat. Juminem tidak serta merta meninggalkan kewajibannya memasak, mengasuh, dan mengurus rumah meskipun ia bekerja. Amat disayangkan Mariyanto tidak peka atas apa yang dijalani Juminem sebagai seorang istri dan pekerja sekaligus.

Rumah tangga adalah sarana agar mereka mampu melakukan komunikasi dengan masyarakat karena rumah tangga bukan sekedar ruang privasi, tetapi ruang terbuka yang dapat diketahui oleh masyarakat di sekitarnya. Hal ini berbeda dengan kebudayaan yang berada di barat dimana anggota masyarakat lebih cenderung individualis, sehingga seorang perempuan hanya terkurung di dalam rumah beserta aktivitasnya. Rukun dan srawung inilah yang menjadi kunci utama para perempuan dapat beriteraksi dan mengembangkan dirinya di masyarakat tanpa meninggalkan tugasnya sebagai poros utama keluarga.

Beberapa penelitian yang memiliki tema sama dengan novel Juminem Dodolan Tempe, telah banyak dilakukan. Penelitian-penelitian tersebut ialah: Erni Triani (2009) berjudul Citra Perempuan dalam Keluarga Kajian Novel Tiga Orang Perempuan karya Maria A. Sardjono: Tinjauan Kritik Sastra Feminis, Kartina Sri Rejeki (2013) berjudul Citra Perempuan Jawa dalam Cerbung Teratai Wungu Karya Ibne Damayanti (Sebuah Kajian Kritik Sastra Feminis), Ai Rohmawati (2013) yang berjudul Citra Perempuan dalam Naskah Ratu Dewi Maleka: Kajian Feminis Ideologis, R. Myrna Nur Sakinah (2014) berjudul Citra Perempuan dalam Novel The Holy Woman : Satu Kajian Feminis.

Oleh karena itu, dari pemaparan di atas penulis akan mengangkat penelitian yang berkenaan dengan penggambaran tokoh perempuan dalam menyikapi berbagai persoalan keluarga dan sosial untuk mengetahui dan memahami lebih dalam cara pandang dan sikap yang diambil. Adapun permasalahannya yaitu citra, sikap dan cara pandang perempuan dalam menghadapi 
persoalan dalam kontruksis sosial bias gender.

Tujuan penelitian ini ialah menemukan, menganalisis dan mendeskripsikan citra, cara pandang dan sikap tokoh perempuan dalam menghadapi persoalan sebagai perempuan modern dalam novel. Penelitian ini diharapkan dapat menambah wawasan dan pengetahuan baru bagi pembaca mengenai citra perempuan Jawa sebagai istri melalui kritik sastra feminis. Penelitian ini juga dapat digunakan pembaca untuk memahami lebih dalam isi yang ingin disampaikan pengarang melalui novel dengan menggunakan kritik sastra feminis.

\section{METODE}

Pendekatan yang digunakan dalam penelitian ini ialah pendekatan objektif Abrams dengan teori kritik sastra feminis. Metode yang digunakan ialah metode deskriptif. Teknik pengumpulan data dan analisis data menggunakan teknik pembacaan heuristik dan hermeneutik (Supriyanto, 2014). Sumber data diperoleh dari novel dengan data berupa bagian novel seperti; ungkapan, persoalan, dan narasi pengarang yang di dalamnya mengandung informasi mengenai citra perempuan dari sudut pandang feminisme (Sugihastuti \& Suharto, 2002). Data kemudian diolah dan diklasifikasikan baik berupa narasi maupun dialog yang memberikan informasi mengenai citra perempuan dari sudut pandang feminisme. Setelah dianalisis, data kemudian disajikan dalam bentuk deskriptif naratif.

\section{HASIL DAN PEMBAHASAN}

Citra fisik yang dimiliki Juminem ialah sosok yang cantik dan molek. Kecantikan dirinya digambarkan secara tersirat oleh pengarang melalui pandangan Mariyanto terhadap Juminem saat memakai baju yang belum pernah dilihat Mariyanto. Kecantikan Juminem sampai membuat Mariyanto selalu memujinya. Tak hanya melalui pandangan Mariyanto, kecantikan Juminem juga dikemukakan oleh orang-orang yang mengenalnya sebagai penjual tempe.

"Cetha lah sing dodol tempe wae blengah-blengah. Apa maneh isih enom.."

"Aku nate weruh sepisan, pokoke wuahh... bakule karo tempene padha, memblak-memblak, semlohe... muntur-muntur kaya anggur. ..." (hlm. 90)

"Jelas dong yang jualan tempe aja molek. Apalagi masih muda, ..."

"Aku pernah melihat sekali, pokoknya waahh... penjualnya sama tempenya sama, menggiurkan, cantik... muntur-muntur kaya anggur. ..."

Pada konteks obrolan di atas, mereka sedang membicarakan Juminem si penjual tempe yang sudah terkenal di pasar karena tempenya yang sangat enak rasanya. Selain itu ia juga dikenal cantik. Kecantikannya hingga membuat orang lain terpesona dan mengibaratkan dengan anggur. Buah anggur, selain bentuknya cantik, harganya mahal dan rasanya enak. Begitulah Juminem digambarkan, selain berparas ayu kualitas tempe buatannya juga bagus.
Citra fisik pada tokoh perempuan hanya terdapat dalam tokoh Juminem. Tokoh Mbok Joyo Pangat dan Minah tidak memiliki citra fisik.

\section{Citra Psikis}

Juminem

Juminem sebagai representasi sosial perempuan Jawa masa kini dapat dilihat dari citraan yang dituliskan pengarang. Ia digambarkan sebagai perempuan berpikiran maju tanpa melupakan hakikatnya sebagai perempuan Jawa. Meskipun tidak berpendidikan tinggi, ia mampu memandang apa yang menimpa dirinya dengan pandangan logis dan realistis. Hal tersebut terlihat dari tanggapannya mengenai jenis pekerjaan yang hendak dituju Mariyanto. Sangat tidak realistis ketika hendak melamar, pihak calon pelamar harus menyerahkan sejumlah uang tertentu. Ia juga berhati-hati mengenai jenis pekerjaan yang belum jelas untuk melindungi diri dari penipuan.

"Kang aku sumelang ... kadhung aku mengko golek utangan, tundhone kowe mung diapusi. Banjur sing dienggo tombok apa?" (hlm. 41)

"Kang aku takut... terlanjur aku nanti mencari hutang, malah engkau ditipu. Lantas yang digunakan untuk tebusan apa?"

Sebagai seorang istri ia tidak lupa akan kewajibannya terhadap suami dan atas apa yang dilakukan Mariyanto kepadanya. Meskipun Mariyanto seringkali menyakiti perasaannya, Juminem tidak lantas meminta cerai. Menurutnya dengan senantiasa berdoa dan yakin akan kuasa Tuhan, segalanya akan berakhir bahagia. Oleh karena itu, ia memilih senantiasa bersikap sabar dalam menghadapi sikap Mariyanto.

"Hhahaha... menawa sakmene ya apa cukup, apa meneh iki esuk isih padha turu," wangsulane Mariyanto nandhesake.

Hmm..." Juminem mung bisa ngelus dhadha.

(hlm. 25)

"Hhahaha... jika segini apa ya cukup, apa lagi ini masih pagi masih pada tidur," jawaban Mariyanto menegaskan.

Hmm..." Juminem hanya bisa mengelus dada.

Seluruh orang tahu perilaku buruk Mariyanto, namun sebagai seorang istri ia tahu bahwa menjaga nama baik Mariyanto adalah suatu keharusan. Itulah yang dilakukannya di hadapan ibu dan saudarinya. Juminem tidak pernah menngatakan keadaan Mariyanto yang sebenarnya di hadapan Mbok Joyo Pangat dan Minah. Ia selalu mengatakan yang baik-baik tentang Mariyanto jika mereka bertanya. Tujuannya agar citra diri Mariyanto tidak buruk di hadapan Mbok Joyo Pangat yang sedari awal sudah tidak menyukainya.

Bertahaan dengan Mariyanto dalam kondisi ekonomi yang sulit dan tekanan psikis tetap membuat Juminem sanggup bertahan karena ia sudah menerima apa yang menjadi takdirnya. Juminem pun melalui segala 
daya dan upaya berusaha memperbaiki ekonomi dengan bekerja membuat dan menjual tempe. Pendapatan yang diperoleh memang tak seberapa, namun ia tetap mampu mengelola keuangan agar kebutuhan tercukupi dengan skala prioritas. Sehari-harinya dihadapkan pada rutinitas padat antara bekerja, mengurus rumah, dan mengasuh putrinya. Pada akhirnya kerja keras dan sikap ngemongnya membuahkan hasil. Pelan tapi pasti Mariyanto menyadari kekeliruannya dan memperbaiki fungsinya sebagai kepala keluarga.

\section{Mbok Joyo Pangat}

Mbok Joyo Pangat digambarkan sebagai janda yang sukses. Ia termasuk janda kaya yang ditakuti dan disegani masyarakat. Semua itu diperoleh atas kerja keras yang dilakukannya selama masih muda. Tentu kerja keras yang dilakukannya diimbangi dengan kecerdasan dan luasnya wawasan yang dimilikinya. Meskipun tinggal di desa, Mbok Joyo Pangat merupakan perempuan yang berpemikiran maju, seperti pada kutipan berikut.

"Mulane nduwe utek kanggo mikir. Menawa gelem manggon ana desa, mengko daktukokna mesin kanggo nggiles. Dakmodhali. Kowe ora nyambut gawe dhewe, ben direwangi tangga-tangga sing nganggur. ..." (hlm. 141)

"Makanya punya otak itu digunakan untuk berpikir. Jika mau tinggal di desa, nanti aku belikan mesin penggiling kedelai. $\mathrm{Ku}$ modali. Kamu tak perlu bekerja membuat sendiri, biar dibantu orang-orang sini yang menganggur... (hlm. 141)

Kecerdasan Mbok Joyo Pangat ditunjukkan dalam kejeliaannya melihat peluang. Ia memiliki jiwa bisnis yang bagus dilihat dari cara pandangnya yang ditujukan pada Juminem terkait penjualan tempenya. Ia akan membiayai semua produksi tempe Juminem dengan cara membelikan mesin penggiling. Dengan menggunkan mesin penggiling, Juminem tidak perlu repot-repot menggilingkan kedelai. Selain itu tentu jumlah produksi tempenya lebih banyak. Ia juga bisa mempekerjakan para tetangganya yang masih pengangguran sehingga menciptakan lapangan pekerjaan di desa. Hal tersebut secara tak langsung juga menunjukkan pemikiran maju Mbok Joyo Pangat meskipun sudah berumur dan sebagai orang desa.

Akan tetapi kesuksesannya telah membutakan Mbok Joyo Pangat akan materi sehingga ia menilai keberhasilan orang lain dari banyaknya harta yang dimiliki. Hal ini berlaku terhadap Juminem ketika memilih calon pasangan hidup. Mbok Joyo Pangat menganggap bahwa Juminem akan bahagia jika dinikahkan dengan tetangganya yang kaya raya. Namun Juminem rupanya lebih memilih Mariyanto sehingga ia tidak menyukai Mariyanto bahkan setelah menjadi menantunya.

\section{Minah}

Digambarkan sebagai perempuan lajang yang menyukai kebebasan, peduli terhadap saudarinya, tidak tegaan, dan berpemikiran terbuka. Wawasan dan relasi yang dimilikinya membuatnya mudah mencari uang. Ia juga tipikal perempuan mandiri yang tidak hanya menghabiskan uang orang tuanya, tetapi berusaha mencukupi kebutuhannya sendiri dengan bekerja. Minah sangat menyayangi Juminem sebagai satu-satunya saudara perempuan yang dimilikinya. Rasa sayangnya diwujudkan dalam bentuk kepeduliaanya akan kesusahan Juminem seperti pada kutipan berikut.

"Oh... ya Yu, kowe butuhmu apa, mengko daktukokna. Aja kwatir dhuwitku akeh, yen perlu ATMku gawanen kanggo sangu uripmu," kandhane Minah saking welase marang mbakyune. (hlm.9)

"Oh... ya Mbak, kamu butuhmu apa, nanti aku belikan. Jangan khawatir uangku banyak, jika perlu ATMku bpokawa untuk kebutuhan hidupmu," kata Minah begitu kasihannya dengan kakaknya.

Ia berulangkali mengatakan bahwa jika Juminem membutuhkan bantuan jangan sungkan untuk meminta tolong. Minah senang mampu membantu Juminem, bahkan ia sampai rela kartu ATMnya dibawa seandainya Juminem memang sangat membutuhkan. Minah tidak pernah merasa rugi membelanjakan uangnya karena ia memiliki uang yang banyak untuk membelikan kebutuhan Juminem. Kebaikannya membuat Juminem merasa terharu. Hal tersebut dilakukan karena ia tak tega melihat Juminem susah.

\section{Citra Sosial}

Juminem

Juminem sebagai anggota sosial tentu memiliki relasi dengan anggota sosial yang lain. Relasi tersebut menimbulkan hubungan timbal balik yang dapat memberikan gambaran atas respon atau sikap yang diambil Juminem dalam relasinya tersebut. Seperti yang dilakukannya ketika mengalami kebimbangan atas rumah tangganya ia membutuhkan nasihat dari tetua agama. Di sini, Juminem memainkan fungsi sebagai makhluk sosial yang tidak dapat berdiri sendiri tanpa bantuan orang lain. Akan tetapi dalam meminta bantuan ia tidak lantas memberatkan orang lain. Hal ini nampak pada keteguhan yang tidak ingin merepotkan Minah dengan meminta bantuan atas kesulitan perekonomiannya. Ia justru segera tanggap dengan melakukan sesuatu untuk menyelamatkan perekonomian keluarga.

Apa yang dilakukannya merupakan bentuk kesadaran sosial dimana hubungan laki-laki dan perempuan dalam rumah tangga adalah saling melengkapi dan menyeimbangkan. Keseimbangan dalam keluarga Juminem dapat tercapai ketika ia mampu menjadi seorang istri yang ubet dan glidhig. Kedua istilah ini memiliki arti yang hampir sama tetapi makna yang berbeda. Seorang perempuan dikatakan ubet ketika ia melakukan berbagai macam kesibukan tanpa melupakan tugas utamanya dalam rumah tangga, terlepas kegiatan tersebut menghasilkan uang atau tidak. Istilah glidhig ialah ketika seorang perempuan melakukan pekerjaan yang dapat menghasilkan uang dan meningkatkan ekonomi keluarga (Permanadeli, 2015: 284-288).

Juminem senantiasa bersikap sumeleh atau menerima dengan lapang terkait perilaku Mariyanto. Peneri- 
maannya tak lantas mendefinisikan dirinya kalah terhadap Mariyanto, akan tetapi sebagai strategi menghadapi keras hati suaminya. Alasannya agar kerukunan dalam rumah tangga tercapai. Sikap sumeleh telah membawa keluarganya kembali normal dengan fungsi masing-masing. Mariyanto akhirnya menyadari tanggungjawabnya sehingga kembali bekerja. Pekerjaan sebagai tukang parkir membuat Mariyanto malu. Namun, oleh Juminem ia dibesarkan hatinya. Ia mendukung dan menerima dengan ikhlas apa yang menjadi matapencaharian suaminya. Ia tidak mengeluh dan menuntut lebih apa yang bisa diberikan Mariyanto.

Individu Jawa mengutamakan kerukunan dalam masyrakat. Rukun ialah saling tolong menolong, menyearaskan kepentingan pribadi dan umum demi terciptanya keselarasan sosial. Sikap Juminem dalam citra rukun ini berbentuk kedermawanan, senang menolong, dan menutupi keresahan hatinya demi terciptanya kerukunan seperti yang dilakukan ketika ia menerima surat dari Kirman.

\section{"Ana apa Jum?" \\ "Ora apa-apa, Kang Man meling menawa dodolan aja padha tukaran, kon sing padha rukun," wangsulane mung ngarang. (hlm. 118) \\ "Ada apa, Jum?" \\ "Tidak apa-apa, Kang Man mengingatkan jikalau jualan jangan saling bertengkar, disuruh yang rukun," katanya hanya mengarang.}

Surat tersebut sebenarnya berupa permintaan Kirman pada Juminem. akan tetapi, agar masyarakat tidak salah praduga, ia mengatakan bahwa isi surat tersebut ialah pesan untuk saling rukun.

\section{Mbok Joyo Pangat}

Sebagai seorang janda yang bekerja keras dalam membesarkan anak-anaknya, Mbok Joyo Pangat terkenal keras, giat, dan tegas. Akan tetapi sangat disayangkan Mbok Joyo Pangat memiliki sifat yang kurang terpuji. Ia terkadang terlalu menyombongkan kekayaannya dan memandang rendah sesama. Kesombongannya terlihat saat ia memandang rendah kondisi rumah Juminem. Sifat tidak menghormati orang lain nampak saat ia merendahkan calon mertuanya hanya karena ia tidak menyukai Mariyanto.

\section{Minah}

Secara sosial Minah adalah perempuan yang modern, tidak kolot, dan suka bepergian. Dirinya yang modern terlihat dari pemikirannya yang terbuka. Keluwesannya yang mampu mandiri secara finansial dengan berjualan kosmetik, pulsa, makelar hasil pertanian, dan sejenisnya. Ketidakkolotannya tercermin dari sikapnya dalam menghadapi ledekan Lik Gimin yang mengatakan bahwa perempuan tidak boleh bepergian tanpa tahu waktu. Bagi Minah, bukan waktunya dan bepergiannya, tapi pengalaman yang didapatkan tanpa melanggar norma-norma sosial.

\section{Sikap Tokoh Perempuan dalam Menghadapi Bias Gender}

Ketimpangan gender, menurut Fakih (2013:12) baik disadari maupun tidak terbentuk dalam berbagai model seperti marginalisasi, subordinasi, pelabelan (stereotipe), kekerasan, dan beban kerja. Marginalisasi ialah suatu keadaan dimana perempuan terpinggirkan atau kurang dihargai. Subordinasi ialah kondisi perempuan yang berada di bawah laki-laki. Stereotip ialah pelabelan yang melekat pada seseorang dan biasanya menjadi anggapan umum. Kekerasan ialah perilaku fisik dan psikis yang diperoleh korban secara berebihan. Keempat model tersebut ada dalam novel dalam bentuk seperti ini.

\section{Marginalisasi}

Kesalahan Mariyanto masih mendapatkan pembenaran karena dalam struktur rumah tangga Jawa, seorang kepala rumah tangga memiliki kuasa dan kontrol penuh terhadap anggota keluarga yang lain. Kekuasaan inilah yang kemudian berimbas pada pola pikir dan perilaku Mariyanto terhadap Juminem. Jika ia berbuat baik, maka selamatlah keluarganya, begitu pun sebaliknya. Ia berpikir bahwa meskipun ia sering menyusahkan Juminem, namun ia seharusnya masih memiliki rasa hormat dari Juminem. Mariyanto pernah menuduh Juminem selingkuh. Dalam menyikapi hal tersebut, Juminem membela dirinya dan tidak tinggal diam. Ia juga adu argumen dengan membalikkan fakta bahwa Mariyanto sendiri tidak bertanggungjawab terhadap tugasnya sebagai seorang kepala rumah tangga.

\section{Subordinasi}

Subordinasi terhadap Juminem ditunjukkan dari rasa takut Juminem menyinggung perasaan Mariyanto. Rasa takut yang dialami Juminem menandakan bahwa ia tidak memiliki kesetaraan dalam menyampaikan pendapatnya Juminem mengalami subordinasi pula dalam melawan kehendak Mariyanto untuk berhubungan suami istri. Melayani suami adalah suatu keharusan dalam keluarga masyarakat Jawa, terlepas dari kondisi apapun. Hanya saja, bentuk pelayanan Juminem terhadap Mariyanto bukan dilandasi rasa saling membutuhkan, tetapi keterpaksaan. Keterpaksaan ini dikarenakan saat itu Juminem sedang melakukan pekerjaannya membungkusi tempe yang harus segera selesai esoknya (Setiyadi, 2016: 43). Akan tetapi, sebagai kewajiban, Juminem pun menuruti kehendak Mariyanto walau pada akhirnya tidak jadi karena putrinya menangis.

\section{Stereotip}

Stereotip terhadap Juminem berupa anggapan dalam dirinya sendiri bahwa ibu rumah tangga memiliki banyak sekali tugas rumah yang tidak boleh diabaikan. padahal Mariyanto sebenarnya juga memiliki peranan membantu Juminem, hanya saja Juminem tidak mau merepotkannya. Kemudian Minah juga mengalami stereotip ketika ia dikatakan sebagai perempuan tak tahu aturan oleh Lik Gimin yang ditunjukkan dalam kutipan berikut. 
dolan karo kancane. Ngeblas rana, sedhela metu mrana. Ora ana kesele yen dolan."

"Jamanku biyen beda. Menawa dolan nganggo wates. Apameneh jenenge bocah wadon, huhhh... ora oleh metu sembarangan. Saiki adhuh..... wong tuwa dadi sumelang terus," Lik Gimin nambahi cerita. (hlm. 7) "Walahh.. Minah ya apa pernah di rumah. Tiap hari bermain dengan temannya. Pergi ke sana, sebentar lagi ke lain tempat. Tidak ada lelahnya jika main."

"Jamanku dulu beda. Jika main memandang waktu. Apalagi namanya anak perempuan, huhhh... tidak boleh keluar sembarangan. Sekarang aduhhh...orang tua menjadi selalu khawatir," Om Gimin menambahkan.

Ketika dituduh seperti itu, tanggapan yang diberi Minah ialah mengelak dan memandang bahwa Lik Gimin masih konservatif. Ia masih meemegang aturan lama yang tidak relevan dengan zaman sekarang. Mobilisasi dan arus informasi begitu cepat sehingga semua orang pun bergerak mengikutinya. Menurut Minah, apa yang dilakukan sudah sesuai dengan zamannya.

\section{Kekerasan}

Juminem mengalami kekerasan terselubung yang di dalamnya terdapat tekanan psikis yang ia terima dari Mariyanto. Ia merasa tertekan atas perilaku dan sikap Mariyanto. Tekanan psikis membuatnya tidak nyaman sehingga berpengaruh pada taraf kesejahteraan hidupnya. Akan tetapi, ia hanya mampu merepresinya dalam bentuk sikap sumeleh dan ngemong yang menunjukkan bahwa ia kuat dalam lemahnya. Ia juga mengalami pelecehan seksual yang berupa lelucon vulgar, ketidaksopanan, dan tuduhan sebagai perempuan lacur. Bahkan tuduhan tersebut diucapkan sendiri oleh Mariyanto. Pelecehan seksual juga dilakukan oleh orang-orang yang mengerti Juminem melalui kabar burung.

\section{Beban Kerja}

Beban kerja yang dialami Juminem berupa peran ganda karena ia harus mencari nafkah serta tetap mengurus rumah dan anak. Beban kerja tersebut bukan hanya dikarenakan oleh keterpaksaan, tetapi juga atas inisiatifnya sendiri. Ia bekerja karena menyadari bahwa hidup ini butuh mangan. Urusan rumah tangganya dilakukan sendiri tanpa bantuan Mariyanto karena ia menyadari Mariyanto tidak pernah dilahirkan untuk melakukan hal tersebut. Juminem hanya menerimanya sembari menyadarkan suaminya agar kembali ke fungsinya sebagai kepala rumah tangga, yaitu mencari nafkah.

\section{SIMPULAN}

Berdasarkan hasil penelitian ditemukan citra fisik, citra psikis, dan citra sosial perempuandalam novel. Citra fisik hanya ditemukan pada tokoh Juminem. Citra psikis ditemukan pada tokoh Juminem, Mbok Joyo Pangat, dan Minah. Citra sosial ditemukan pula pada tokoh Juminem, Mbok Joyo Pangat, dan Minah. Terdapat bias gender yang meliputi marginalisasi, stereotip, subordinasi, kekerasan, dan beban kerja serta sikap yang diambil tokoh perempuan dalam menghadapi bias gender tersebut.

\section{DAFTAR PUSTAKA}

Fakih, Mansour. 2013. Analisis Gender \& Transformasi Sosial. Yogjakarta: Pustaka Pelajar.

Koesbandijah, S., Wasino, \& Astuti, T. M. P. (2013). Relasi Gender Dalam Komunitas Miskin Dukuh Kayon Desa Batursari Kecamatan Mranggen Kabupaten Demak. Journal of Educational Social Studies, 2(1), 8-15. Diambil dari htttps://journal.unnes.ac.id/sju/index.php/ jess/article/view/1295

Lantara, N. F. (2015). The Roles of Woman as Leader and Housewife. Journal of Defense Management, 5(1), 1-5. https://doi.org/10.4172/2167-0374.1000125

Permanadeli, Risa. 2015. Dadi Wong Wadon :Representasi Sosial Perempuan Jawa Di Era Modern.Sleman: Pustaka Ifada.

Prabasmoro, Aquarini Priyatna. 2007. Kajian Budaya Feminis. Yogyakarta: Jalasutra.

Setiyadi, Tulus. 2016. Juminem Dodolan Tempe? Surabaya: Padang Ilalang.

Sugihastuti \& Suharto. 2002. Kritik Sastra Feminis: Teori dan Aplikasinya. Yogyakarta:Pustaka Pelajar.

Supriyanto, Teguh. 2014. Kajian Stilistika dalam Prosa. Yogyakarta: Elmetera Publishing. 